\title{
PENGORGANISASIAN DALAM PERENCANAAN PEMASARAN
}

\author{
Hanan Fakhira Sa'diyyah \\ Naura Aulia Hafidzah \\ Muhammad Zaidan Mubarak \\ Mumuh Mulyana \\ Sofie Kurnia Asih
}

Selamat berjumpa lagi. Di penghujung pertemuan ini, saya berharap para mahasiswa tetap semangat.

Inisiasi VIII membahas materi Pengorganisasian Perencanaan dalam Perencanaan Pemasaran. Seperti biasa, silahkan pelajari modul 9 dari BMP Perencanaan Pemasaran (EKMA 4569).

Jangan lupa untuk mengerjakan tes formatif modul 9 untuk mengevaluasi kemampuan pemahaman Anda tentang materi tersebut.

Kompetensi Umum : Mahasiswa diharapkan mampu memahami dan menjelaskan konsep dasar dan perancangan perencanaan pemasaran serta aplikasinya dalam bauran pemasaran

Kompetensi Khusus $\quad$ : Mampu menjelaskan dan Merumuskan Pengorganisasian dalam Perencanaan Pemasaran

Menjelaskan Peranan Informasi pemasaran dan peramalan dalam perencanaan pemasaran

Memahami Penelitian pemasaran

Menjelaskan Perencanaan segmentasi

Menjelaskan Sumber informasi untuk segmentasi

Menjelaskan Pengorganisasian untuk perencanaan pemasaran

\section{Sumber Belajar}

1. Utama

Modul 9 EKMA4569

Perencanaan Pemasaran. Daniel Tumpal. Universitas Terbuka. 2016

2. Tambahan:

- Marketing Management : A Strategic Decision-Making Approach. John W. Mullins and Orville C. Walker, Jr. $7^{\text {th }}$ edition. McGraw-Hill International Edition. 2010

\section{Rangkuman Materi Kuliah}


Tren perubahan yang semakin cepat dalam dunia pemasaran mengharuskan perusahaan untuk mampu bergerak bersama dengan perubahan tersebut sesuai dengan kapasitas yang dimiliki. Satu kegiatan yang harus dilakukan adalah mempersiapkan diri untuk mengantisipasi perubahan yang akan terjadi di masa yang akan datang. Caranya adalah dengan melakukan peramalan (forecasting).

Peramalan yang dilakukan meliputi peramalan makro dan/atau peramalan mikro. Penentuan peramalan tersebut didasari pada 4 faktor, yaitu tingkat akurasi yang diharapkan, ketersediaan data dan informasi, waktu peramalan, serta posisi produk pada daur hidup produk. Peramalan makro dilakukan mendahului penetapan sasaran dan strategi pemasaran, sedangkan peramalan mikro dilakukan setelah perusahaan memutuskan peluang pasar spesifik mana yang akan dipilih dan bagaimana cara terbaik mengelolanya. Dan secara teknis ada 2 (dua) cara dalam melakukan peramalan, yaitu secara kuantitatif dan kualitatif.

Agar dapat melakukan peramalan dengan efisien dan efektif diperlukan data atau informasi yang akurat. Informasi tersebut diperoleh melalui penelitian pemasaran yang diartikan sebagai suatu upaya pencarian informasi untuk memenuhi keinginan konsumen. Penelitian pemasaran yang baik memperhatikan unsur-unsur, yaitu: relevan terhadap kebutuhan, tepat waktu, efisien dibandingkan dengan biaya yang dikeluarkan, serta akurat.

Dilihat dari tujuannya, penelitian pemasaran dapat diklasifikasikan menjadi penelitian identifikasi masalah dan penelitian pemecahan masalah. Penelitian identifikasi masalah bertujuan untuk mengangkat masalah yang tersembunyi yang mungkin telah terjadi atau akan terjadi, sedangkan penelitian pemecahan masalah adalah untuk memperoleh solusi atas masalah yang dihadapi.

Secara umum tahapan-tahapan dalam penelitian pemasaran meliputi perumusan masalah; penentuan desain riset; perancangan metode pengumpulan data; perancangan sampel dan pengumpulan data; analisis dan interpretasi data; serta penyusunan laporan riset. Dalam pelaksanaannya, penelitian pemasaran bisa dilakukan sendiri oleh perusahaan dan bisa juga melalui jasa penyedia layanan penelitian pemasaran.

Hal penting lainnya yang perlu diperhatikan oleh perusahaan sebelum membuat perencanaan pemasaran ialah menganalisis dan menentukan segmen pasar mana yang dimasuki. Ada dua pendekatan yang umumnya dipakai dalam melakukan segmentasi, yaitu pendekatan apriori dan pendekatan post hoc. Pada pendekatan apriori, perusahaan mempercayai segmentasi yang telah ada/ditetapkan sebelumnya sedangkan pendekatan post hoc adalah menganalisis kembali data konsumennya. Pendekatan post hoc lebih akurat dibandingkan pendekatan apriori karena data yang dikumpulkan itulah yang berbicara sebagai kenyataan yang terjadi di lapangan.

Pendekatan post hoc dapat dikerjakan melalui dua metoda, yaitu metoda dependensi dan metoda interdependensi. Dalam metoda dependensi, segmen-segmen dibentuk dari hubungan antara variabel terikat (dependent variable) dengan sejumlah variabel bebas (independent variable). Variabel terikat merupakan atribut yang mencerminkan kegiatan konsumen yang penting bagi perusahaan, seperti pola pemakaian produk, kepuasan akan merek, kesetiaan akan merek dan sebagainya. Variabel bebas merupakan faktor-faktor yang mempengaruhi konsumen melakukan kegiatan tersebut. Misalnya usia, jenis kelamin, pendidikan, penghasilan, sikap, dan lain-lain. Diharapkan keluaran dari analisis tersebut perusahaan dapat mengetahui faktor apa yang paling mempengaruhi variabel terikat serta dapat mengidentifikasi segmen yang berbeda menurut variabel-variabel yang ada. 
Pada metoda interdependensi segmentasi hanya ditentukan oleh variabel-variabel bebas. Variabel bebas tidak harus dihubungkan dengan variabel terikat. Tujuannya adalah untuk menemukan segmen-segmen yang memiliki kesamaan respons terhadap variabel-variabel bebas tertentu. Variabel-variabel bebas tersebut dinyatakan dalam bentuk pernyataan-pernyataan. Setiap pernyataan disebut variabel dimana variabel tersebut mewakili karakter tertentu konsumen. Contohnya perilaku terhadap merek terdiri atas karakter usia, jenis kelamin, pendidikan, jumlah anggota keluarga, status pernikahan, dan lain-lain.

Hal penting lainnya dalam perencanaan pemasaran adalah setiap perusahaan harus merancang organisasi atau departemen pemasaran yang dapat melaksanakan strategi dan rencana pemasarannya.

Jenis struktur yang paling umum adalah organisasi fungsional. Di bawah struktur ini, berbagai kegiatan pemasaran dikepalai oleh seorang spesialis, sebagai contoh, sebagai manajer media sosial akan bertanggung jawab atas semua kegiatan media sosial dan melaporkan kepada direktur pemasaran. Struktur pemasaran fungsional ini beroperasi di semua produk dan geografi. Perusahaan yang menjual lintas negara atau internasional, sering menggunakan organisasi geografis. Tenaga pemasarannya ditugaskan ke pasar geografis tertentu, yang memungkinkan mereka untuk menetap di suatu wilayah, memahami pelanggan dan bekerja dengan waktu dan biaya perjalanan yang minimal.

Perusahaan dengan berbagai produk atau merek sering membuat struktur pemasaran manajemen produk. Dengan menggunakan strategi ini, seorang manajer pemasaran produk mengembangkan dan mengimplementasikan strategi pemasaran yang lengkap dan program untuk spesifik produk atau merek tertentu.

Untuk perusahaan yang menjual satu produk ke berbagai jenis pasar dan pelanggan, pasar, atau struktur manajemen pelanggan mungkin yang terbaik. Pemasar dalam struktur manajemen pasar bertanggung jawab untuk mengembangkan strategi pemasaran untuk pasar atau pelanggan tertentu. Perbankan VIP adalah contohnya.

Organisasi pemasaran telah menjadi masalah yang semakin penting dalam lanskap bisnis saat ini.

Dengan banyak perusahaan yang menemukan bahwa lingkungan membutuhkan lebih sedikit fokus pada produk, merek, dan wilayah, dan lebih banyak fokus terhadap keterlibatan dan manajemen pelanggan.

\section{Referensi :}

[1] Tumpal, Daniel, 2016. Perencanaan Pemasaran. Universitas Terbuka.

[2] McDonald, Malcolm and Wilson, Hugh. 2011. Marketing Plans: How To Prepare Them, How To Use Them. $7^{\text {th }}$ edition. Wiley.

[3] Mullins, John W. and Walker, Jr. Orville C., 2010. Marketing Management : A Strategic Decision-Making Approach. $7^{\text {th }}$ edition. McGraw-Hill International Edition. 
[4] O’Guinn, Thomas C.; Allen, Chris T. and Semenik, Richard J., 2009. Advertising \& Integrated Brand Promotion. $5^{\text {th }}$ Edition. South-Western Cengage Learning.

[5] Crawford, Merle and Benedetto, Anthony Di 2011. New Products Management. $10^{\text {th }}$ Edition. McGraw-Hill International Edition. 2011.

[6] Mulyana, Mumuh. 2019. "STRATEGI PROMOSI DAN KOMUNIKASI.” INA-Rxiv. June 12. doi:10.31227/osf.io/v7dfr.

[7] Mulyana, Mumuh. 2019. "MENGANALISIS PERILAKU KONSUMEN.” INA-Rxiv. June 12. doi:10.31227/osf.io/2wj34.

[8] Mulyana, M., 2012. Consumer Behaviour: Sukses Dengan Memahami Konsumen.

[9] Mulyana, M. and Sulistiono, S., 2012. Kewirausahaan: The Long Life Way of Business.

[10] Pauziah, P. and Mulyana, M., 2018. Formulation of The Green Marketing Development Strategy for the Body Shop Botani Square Bogor. In THE INTERNATIONAL CONFERENCE ON ACCOUNTING AND MANAGEMENT SCIENCE (p. 171).

[11] Hidayat, L., Mulyana, M. and Effendy, M., 2018. Membangun Kepuasan Mahasiswa Pengguna Laboratorium Komputer. JAS-PT Jurnal Analisis Sistem Pendidikan Tinggi, 1(2), pp.93-101.

[12] Mulyana, M., PERSEPSI DAN PERILAKU KONSUMEN TERHADAP ONLINE SHOPPING. 